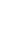

\title{
Exploring epistemological beliefs and learning approaches in context: A sociocultural perspective
}

\author{
Huy P. Phan
}

School of Education, The University of the South Pacific, Suva

\section{Republic of Fiji Islands}

Huy P. Phan. School of Education, Room H408. Faculty of Arts and Law. The University of the South Pacific, Laucala Campus. Suva, Republic of Fiji Islands. E-mail: phan_h@usp.ac.fj

(C) Education \& Psychology I+D+i and Editorial EOS (Spain) 


\begin{abstract}
Background. Research investigation into epistemological beliefs and students' approaches to learning (SAL) from a qualitative perspective has been limited to a few studies. In particular, very research has attempted to explore the origin of personal epistemology and its relation with SAL, taking into account the sociocultural background and personal experience of an individual.
\end{abstract}

Aims. This research examines, qualitatively, the origin of personal epistemology and learning approaches of tertiary students from a sociocultural perspective.

Sample. Participants were 24 tertiary students (14 women, 10 men) of Indo-Fijian and Pacific Islander backgrounds.

Method. Semi-structured interviews were used to explore the origin of personal epistemology and its relation with SAL. Thematic and content analyses were performed to elicit information pertaining to the two theoretical frameworks within the sociocultural milieu of the South $\mathrm{Pa}$ cific.

Discussion. Personal beliefs about the nature of knowledge and knowing originate, in part, from the sociocultural milieu of each individual. Findings concerning personal epistemology differ from previous theoretical account (Baxter Magolda, 1987; Schommer, 1990) and offer additional insight into students' reported beliefs. Finally, there is a collective view that a surface approach to learning is preferred and used extensively by tertiary students.

Keywords: Epistemological beliefs, sociocultural settings, contextualization, learning approaches, tertiary students 


\section{Resumen}

Introducción. La investigación sobre las creencias epistemológicas y los enfoques de aprendizaje de los estudiantes (SAL) desde una perspectiva cualitativa se ha limitado a algunos estudios. De forma particular, muchas investigaciones han intentado explorar el origen de la epistemología personal y su relación con SAL considerando el contexto sociocultural y la experiencia personal del individuo.

Objetivos. El estudio examina, de forma cualitativa y desde una perspectiva sociocultural, el origen de la epistemología personal y los enfoques de aprendizaje de estudiantes universitarios de tercer curso.

Muestra. Los participantes fueron 24 estudiantes universitarios de tercer curso (14 mujeres, 10 hombres) de origen Indo-Fijiano y de las islas del Pacífico.

Método. Se utilizó la entrevista semi-estructurada para explorar el origen de la epistemología personal y su relación con SAL. Se realizaron análisis temáticos y de contenido para obtener información sobre los, teóricamente, dos grupos del medio sociocultural del Pacífico Sur.

Discusión. Las creencias personales sobre la naturaleza del conocimiento y el saber dependen, en parte, del medio sociocultural del individuo. Los resultados sobre epistemología personal difieren de otros estudios previos (Baxter Magolda, 1987; Schommer, 1990) y ofrecen una nueva visión de las creencias de los estudiantes. Finalmente, existe evidencia de que el enfoque de aprendizaje superficial es el preferido y más usado por los estudiantes universitarios de tercer año.

Palabras Clave: Creencias epistemológicas, ambiente sociocultural, contextualización, enfoques de aprendizaje, universitarios

Received: 14/05/08 Initial Acceptance: 15/05/08 Definitive Acceptance: 16/09/08 


\section{Introduction}

The need to investigate students' epistemological beliefs and approaches to learning from a qualitative perspective, taking into account sociocultural settings, arises from theoretical, empirical, and methodological reasoning. Examination of the literature into epistemological beliefs and learning approaches suggests that the main methodological approach employed in previous studies has been correlational and experimental in nature. The complexity of epistemological beliefs, according to some researchers (Hofer, 2004; Schraw \& Sinatra, 2004), cannot simply be gauged from Likert scale instruments or experimental manipulation alone. Our interest in using a qualitative approach to explore epistemological beliefs and learning approaches emerges from two main reasons. First, the issue pertaining to the social and cultural origins of epistemological beliefs has been raised by a number of researchers. The work of Mugler, Richardson, Phan and their colleagues (Mugler \& Landbeck, 1997; Phan, 2008a, 2008b) involving Pacific Islands and Indo-Fijian students has placed an important emphasis on the social environment and one's socio-historical background. This theoretical contention warrants the need to situate students' epistemological beliefs and their learning approaches in a sociocultural framework. According to McCaslin and Hickey (2001), learning, motivation, and one's identity are closely situated in context, specifically to participation in the activities of a community where learning is practiced and valued. It is more than plausible to indicate perhaps, that based on McCaslin and Hickey's grounding, questions such as "How do I know what I know?" (Hofer, 2004) and "Where does the knowledge I acquire come from?" may in fact be researched and interpreted socially and contextually. In this analysis, there is a need to explore from the students' perspective the notion of what knowledge is, and to address the question regarding the theoretical dimensions of epistemological beliefs.

Second, consonant with personal epistemology researchers have contended also with the embedment of students' approaches to learning in social and cultural contexts (Mugler \& Landbeck, 1997; Phan \& Deo, 2007, In press). The same argument may extend to the theoretical conception of learning approaches (Biggs, 1987; Marton \& Säljö, 1976); for example, does the preference for a particular learning approach depend, in part, on the influence of one's social and cultural settings? Are there specific or other approaches to learning, other than the ones that have been described theoretically in previous research?

The focus of this study then, is to extend the work of epistemological beliefs and learning approaches by employing a qualitative research paradigm (Brewer, 2005; Esterberg, 
2002; Merriam, 1998). Methodologically this exploratory study combines the use of semistructured interviews with 24 tertiary students of Pacific Islands and Indo-Fijian origins. It is anticipated that the qualitative data collected may provide relevant information pertaining to the origin of epistemological beliefs and students' learning approaches. In particular, evidence established from this study could elucidate how students' beliefs about the nature of knowledge and knowing are formulated and developed and, more importantly, whether these beliefs and students' approaches to their learning are grounded in a sociocultural context.

\section{Theoretical overview of epistemological beliefs and learning approaches}

Epistemological beliefs arise from the work of Perry (1970) and have emerged recently as an important line of research inquiry (Schraw \& Sinatra, 2004). Epistemology is a branch of philosophy that concerns with the nature of knowledge and justification of beliefs. Different methodological examinations and theoretical models of epistemological beliefs (for example, Baxter Magolda, 1987; Kitchener \& King, 1981; Ryan, 1984) in empirical research, suggest that dimensions of epistemology exist as a continuum (Hofer, 2004; Hofer \& Pintrich, 1997). The work of Schommer indicates, alternatively, the notion that the dimensions of personal epistemology identified may be more or less independent, but each can be represented along a continuum from less sophisticated to more sophisticated beliefs (Schommer, 1990; Schommer-Aikins, 2002). In general, however, central to the study of personal epistemology is the emphasis on: (i) the nature of knowledge (what one believes knowledge is), and (ii) the nature or process of knowing (how one comes to know)(Hofer, 2001; Nist \& Holschuh, 2005). The nature of knowledge includes the dimensions certainty of knowledge and simplicity of knowledge, and the process of knowing includes the dimensions source of knowledge and justification of knowledge (See Table 1)(Hofer, 2004; Hofer \& Pintrich, 1997).

Different theoretical and methodological examinations of personal epistemology have resulted in extensive research exploring the relations between epistemological beliefs and motivation, learning, cognition, and academic performance (Hofer \& Pintrich, 1997; Muis, 2004; Schommer, 1993). The work of Marlene Schommer during the past decade, for example, has been crucial in illustrating the multidimensionality of personal epistemology using the Epistemological Questionnaire (Schommer, 1990, 1994a, 1994b; Schommer-Aikins \& Hutter, 2002). Subsequent studies have also provided empirical evidence emphasising the predictive relations between epistemological beliefs and various aspects of academic perfor- 
mance, important amongst them include comprehension, metacomprehension, interpretation of information, higher-order thinking, persistence in working on difficult academic tasks, and problem-solving approaches (Muis, 2004; Schommer, 1998; Schommer, Crouse, \& Rhodes, 1992; Schommer-Aikins, Duell, \& Hutter, 2005). For example, similar to other motivational constructs in learning, beliefs about structures and certainty of knowledge predict comprehension, metacomprehension, and interpretation of information. Beliefs about the speed of learning and the ability to learn predict comprehension, valuing of education and overall performance. Aligning to specific subject areas, research has also explored the relations between students' epistemological beliefs and study strategies and problem solving in accounting, history, mathematics, and hypermedia learning (Buehl \& Alexander, 2005; Peng \& Fitzgerald, 2006; Phillips, 2001; Schommer-Aikins et al., 2005).

Table 1. Components of epistemological beliefs*

\begin{tabular}{|c|c|}
\hline \multirow{2}{*}{\multicolumn{2}{|c|}{$\begin{array}{c}\text { Core dimensions } \\
\text { Nature of knowledoe }\end{array}$}} \\
\hline & \\
\hline - Certainty of knowledge & $\begin{array}{l}\text { Degree to which one views knowledge as certain; for ex- } \\
\text { ample, absolute truth to one knowledge that is tentative and } \\
\text { evolving (Schommer, 1990) }\end{array}$ \\
\hline - Simplicity of knowledge & $\begin{array}{l}\text { Knowledge that may be seen as an accumulation of facts to } \\
\text { knowledge that is consisted of highly interrelated concepts } \\
\text { (Schommer, 1990) }\end{array}$ \\
\hline $\begin{array}{l}\text { Nature of knowing } \\
\text { - Source of knowledge }\end{array}$ & $\begin{array}{l}\text { This may be seen as knowledge that originates outside the } \\
\text { self and residing in external authority, or it may be per- } \\
\text { ceived as knowledge that is constructed by the individual in } \\
\text { his/her interaction with the environment and others (Baxter } \\
\text { Magolda, 1992) }\end{array}$ \\
\hline $\begin{array}{l}\text { - Justification for kno- } \\
\text { wing }\end{array}$ & $\begin{array}{l}\text { This is referred to how individuals evaluate knowledge } \\
\text { claims, including the use of evidence, the use they make of } \\
\text { authority and expertise, and their evaluation of experts (Ho- } \\
\text { fer \& Pintrich, 1997) }\end{array}$ \\
\hline
\end{tabular}

*Note: As discussed in Hofer (2004)

Student approaches to learning (SAL), similar to personal epistemology, originates in the late 70s. The qualitative work of Marton and Säljö (1976), in particular, identified two main approaches to learning - surface and deep. Students may adopt a deep approach, which entails an intention to understand meaning and linking it to prior knowledge and personal ex- 
perience. In contrast, students may take a surface approach, where the main emphasis is on studying merely for the intention of reproducing information without any further analysis (Murphy \& Tyler, 2005). Based on this theoretical framework, other researchers (Biggs, 1987; Ramsden, 1979) have added an 'achievement' learning component that is contextdependent. The achievement learning approach, according to Biggs (1987), is based on achieving motivation and involves strategies which students believe will lead to high marks; for example, 'study skills' techniques (e.g., good organisation, speed reading, effective notetaking) and 'cue-conscious' strategies that depend on the learning environment and the extent of teach involvement (Akande, 1998).

Empirical research in learning approaches has been extensive with focus made on two main lines of inquiry, namely the relationship between approaches to learning and achievement outcomes (e.g., Drew \& Watkins, 1998; Phan, 2007; Watkins, Regmi, \& Astilla, 1991; Watkins, 2001), and the factor structure of SAL (e.g., Biggs et al., 2001; Kember \& Gow, 1991; Kember \& Leung, 1998; Richardson, 1994). More recently, research investigation has explored the amalgamation of relations between learning approaches, personal epistemology, and academic performance. Evidence suggests that students' learning approaches are a product of personal epistemology which, in turn, make a contribution to the prediction of academic performance (Phan, 2008a). For example, the work of Cano (2005) with Spanish secondary school students showed that simple knowledge and quick learning influenced academic performance indirectly via deep and learning approaches. Furthermore, Cano reported that certain knowledge exerted an indirect effect on academic performance via a surface learning approach. In a study involving tertiary students in the area of Curriculum studies, Phan (2006) found that simple knowledge and fixed ability beliefs made an indirect contribution to academic performance via a deep learning approach. Phillips' (2001) study involving Accounting students found that the dimension of knowledge is complex influenced academic performance via the study strategies of consolidating knowledge. Based on the combining evidence, it would seem then that students with sophisticated beliefs would normally prefer to use a deep learning approach, and use a surface approach when the context demands it. In contrast, students who hold naïve beliefs may tend to view a surface learning approach as being the only approach to use (Phan, 2008a). 
Research investigation of epistemology from a cultural perspective to date is very limited to a few studies (Hofer \& Pintrich, 1997). Research attesting to students' approaches to learning has, in contrast, been more substantial, with studies conducted in Asian (Biggs, Kember, \& Leung, 2001; Kember, 2000; Kember \& Leung, 1998; Wong \& Watkins, 1998) and Pacific contexts (Mugler \& Landbeck, 1997; Richardson, Landbeck, \& Mugler, 1995; Phan, 2007; Phan \& Deo, 2007, In press). Research in epistemological beliefs has included the theoretical frameworks of Schommer (Schommer, 1990; Schommer-Aikins, 2002) amongst others (for example, Baxter Magolda, 1987, 1992) in Western and other contexts. Students' beliefs about the nature of knowledge and learning are unquestionably shaped and influenced by specific cultural and social contexts (Hofer \& Pintrich, 1997). Various researchers have argued, for example, that the notion of interdependence in some collectivist societies may, in fact, influence students' beliefs (Chen, Stevenson, Hayward, \& Burgess, 1995; Triandis, 1989; Triandis, Bontempo, Villareal, Asai, \& Lucca, 1988). In societies where the emphasis of the self is on the individual (Markus \& Kitayama, 1991), personal beliefs and theories about knowledge and knowing are more inclined toward independent thinking and not on the acceptance of agreement (Hofer \& Pintrich, 1997).

In essence, there is a need to research the development of personal epistemology and learning approaches, taking into account one's sociocultural origins (Hofer, 2004). Empirical evidence in the context of the Pacific region, at present, suggests there is credence to further research investigation into the relations between epistemological beliefs and approaches to learning. Extant research studies by Mugler, Phan, and their colleagues (Mugler \& Landbeck, 1997; Phan \& Deo, 2007, In press; Richardson et al., 1995) in learning approaches, and the work of Phan (2006, 2008a, 2008b) in personal epistemology have advocated the importance of one's sociohistorical milieu. The theoretical contention, arising from a number of reasons, underlies the belief that personal epistemology and learning approaches are deeply embedded in the sociocultural and family environments of individuals. First, the Pacific has unique cultural and social values. The ethos of this region bestows on her peoples a set of ideologies and philosophies that may, in fact, shape the perceptions and epistemologies of the teaching and learning processes (Phan, 2007; Phan \& Deo, in press). South Pacific societies place important emphasis on traditional and informal experiences in learning (Puamau, 2002; Taufe'ulungaki, 2002; Thaman, 1999). Individuals growing up in this region are encompassed 
by the notion of respect for the authority, belief in collectivism, unquestioning acceptance of knowledge as being 'truthful', and the entrenched silence as a status quo (Nabobo-Baba, 2006; Ninnes, 1991; Teaero, 2002). Any behaviour that is contrary to the status quo is perceived as a sign of disrespect and disobedience to the authority. For many individuals, embracing the 'traditional practice' of learning and knowing is perceived as having excellent cultured upbringing (Nabobo-Baba, 2006). This traditional practice of learning, according to many scholars, espouses the view that knowledge, as being 'divined' and 'fixed', should be accepted unconditionally.

Secondly, knowledge and knowing, according to many individuals in this region are a product of their cultures. Culture in this sense does not imply simply, say, an Indo-Fijian culture or a Tongan culture. Culture in this case, according to Mugler and Landbeck (1997), involves more than just cultural diversity per se, and includes for example - schools' institutional culture, home (rural and urban) culture, and remote, small islands' culture. In this analysis, there is some recognition and observation that individuals' particular culture, whether it is a distinct culture from a remote village in Fiji, or an outer island's culture from one small island off the coast of Tonga, may in fact embody differing beliefs concerning the source and nature of knowledge and knowing. Individuals who come from a culture that is considered as 'backward' in modernity would, when compared to those who are more culturally urbanised, differ in their views regarding the nature of knowledge and knowing (Ninnes, 1991). The remoteness of certain areas in the South Pacific has helped maintain and uphold the status quo in beliefs and values of what knowledge and knowing should be. For many rural homes and remote schools, for example, the status quo has emphasised that questioning the authority is unjust and non-existing. Knowledge, as being unchangeable and uncontested, is passed on to those who are less able from authority figures or those who hold high social status or power. Furthermore, the traditional way of knowing, unlike their Western counterparts, operate as a collective society where sharing and communal learning are emphasised excessively. This collectivism, as observed in the Pacific Islanders, posits the notion that personal accomplishment is not about the self, but concerns with the fulfilment of honour, respect, and pride for the community at large.

The sociocultural milieu of the South Pacific at present also contributes to the changing view of formal education (Mugler \& Landbeck, 1997; Phan \& Deo, in press). Transcending rapidly is the acceptance that formal education is a perpetuated phenomenon that elevates 
social and economical mobility (Phan \& Deo, 2006). Many individuals in urban locations are embracing, willingly, the Western education system as this is perceived as an instrument that may provide an alternative route to success and a better life. Other scholars (Nabobo-Baba, 2006; Phan \& Deo, In press) have argued that contemporary societies in the South Pacific, with the ongoing social and economical development, are encouraging and nurturing individuals to view education in a favourable light as this brings forth good prospect. In this analysis, parental expectations and the competiveness of societies at large inculcate to individuals from an earlier age to do whatever it takes to succeed academically. Research has shown, for example, that students in general resort to specific learning styles that are conductive specifically to producing good academic performance grades (Mugler \& Landbeck, 1997; Phan, 2007; Phan \& Deo, 2007, in press).

Examination of the present teaching and learning processes in the South Pacific, in accord with students' motives to excel academically, suggests the emphasis is on producing performance-based outcomes (Phan \& Deo, 2006, 2007). Many students in this region select an appropriate approach to learning that enables them to achieve good academic grades quickly. Teachers, in contrast, engage in teaching pedagogies that may be considered as 'transmissive', 'authoritarian', and 'non-reflective' from the students' perspectives. These specific teaching styles have been argued to result in an ongoing cycle that perpetuates non-reflective practice and indoctrination (Phan, 2007). In this analysis, given the disparity between the traditional way of knowing and the Western formal education system, students themselves are in a state of dilemma as to what knowledge should be and how one should proceed to acquire this knowledge. Socio-historical traditions and beliefs, on one hand, see knowledge and learning as being truthful, uncontested and socially communal in nature. On the other hand, formal education, exam-driven curricula, and contemporary societal expectations and values to compete academically place more emphasis on the self and the understanding of individualism. One could argue, based on this dichotomy that differing beliefs about knowledge and how individuals approach their learning are subject to environmental milieus and sociohistorical experiences.

In summary then, there is considerable impetus for us to explore the origin of personal epistemology and the approaches to learning that students adopt, taking into account the sociocultural milieu and personal background of the South Pacific. In this analysis, the cultural context and personal background pertain to a number of important aspects, for example, stu- 
dents' own previous elementary and secondary school experiences, the traditional ways of knowing and learning, society's values and expectations, and the exam-driven curricula and teaching pedagogies that are presently being used by teachers in this region. These factors, in our view, may interact to influence students' formulation and development of their epistemological beliefs. How epistemological beliefs then influence students' approaches to their learning, taking into consideration the sociocultural environment, is also a contentious issue.

A qualitative approach to researching personal epistemology and learning approaches in this study is advantageous, as it enables us to explore the underlying origin and learning strategies of the South Pacific region. In reference to the latter point concerning learning approaches, for example, a qualitative approach may provide relevant information into different learning strategies that cannot be captured solely from Likert-scale inventories. The same premise also applies to the embedment of personal epistemology in the sociocultural milieu and personal experience of individuals. Examination of personal epistemological beliefs from a personal account and originating in sociocultural settings is more detailed and enriching from a qualitative perspective. In particular, we address two questions in this study: (1) How are students' beliefs concerning the nature of knowledge and knowing manifested?, and (2) Do students' personal beliefs concerning knowledge and knowing relate to their preference and use of learning strategies? From a sociocultural perspective, our research interest is concerned with whether students' personal epistemological beliefs and their learning approaches reflect the theoretical dimensions (e.g., knowledge is fixed) discussed previously in epistemology (for example, Schommer, 1990; Schommer et al., 1992; Schommer-Aikins et al., 2005) and learning approaches (Biggs, 1987; Biggs et al., 2001; Phan \& Deo, 2007).

\section{Method}

\section{Participants}

Twenty-four (14 women, 10 men) third-year university students enrolled in the course Educational Psychology participated in this qualitative case study. The ages of the students (10 Melanesians, 6 Polynesians, 4 Micronesians, 4 Indo-Fijians) ranged from 20-42 (M=32.2; $\mathrm{SD}=7.15)$. The interviews took place in the principal researcher's office at the time of convenience, but Saturday was usually the preferred day (as explained below). The students at the outset were explained the purpose of the interviews and no remuneration was provided at any time. 


\title{
Methodological approach: Interview
}

In approaching this qualitative study, we noted the different interview techniques that could be used to document students' beliefs about the nature of knowledge and knowing, as well as their learning approaches in sociocultural contexts. The purpose of interviewing people is to obtain information concerning a person that, otherwise, is not feasible from methods such as observations (Fraenkel \& Wallen, 2006). As Patton (1990) comments:

\begin{abstract}
We interview people to find out from them those things we cannot directly observe. The issue is not whether observational data is more desirable, valid, or meaningful than self-report data. The fact of the matter is that cannot observe everything. We cannot observe behaviours that took place at some previous point in time. We cannot observe situations that preclude the presence of an observer. We cannot observe how people have organised the world and the meanings they attach to what goes on in the world. We have to ask people questions about those things. The purpose of interviewing, then, is to allow us to enter into the other person's perspective. (p. 196)
\end{abstract}

Educational and social theorists have, in general, referred to different accounts of interview, for example - Highly structured/standardised, Semistructured, and Unstructured/Informal (Esterberg, 2002; Legard, Keegan, \& Ward, 2004; Rubin \& Babbie, 2008). Interview procedures, however, do not have to necessarily demarcate into separate boundaries and may, instead, exist on a continuum (see Merriam, 1998, p. 73). In this study, we employed a semistructured interview (also known as in-depth interviews) approach. The main objective of semistructured interviews, according to Esterberg (2002), is "to explore a topic more openly and to allow interviewees to express their opinions and ideas in their own words" (p. 87). More importantly, the use of in-depth interviews enables the researcher to explore a topic such as personal epistemology and learning approaches in detail, as well as to establish and construct theory. For the most part, semistructured interviews are guided by a list of questions and/or issues that need to be explored, and neither the exact wording nor the order of the questions is predetermined (Merriam, 1998). This position also enables the researcher, during the interviewing process, to probe for answers to ascertain additional information on the topic at hand (Kervin, Vialle, Herrington, \& Okely, 2006). 
In our interviews with the 24 participants, we used the recommendations set out by previous researchers (Esterberg, 2002; Legard et al., 2004; Robson, 2002). There are a number of stages that are considered as being relevant in the interviewing process; for example: creating an interview guide to assist in the interview, establishing a location (in this case, in the principal researcher's office) as well as rapport with the participants, and introducing and explaining to the participants the research topic under investigation (Kvale, 1996). We developed an interview guide (Merriam, 1998) that included key themes and words to help us focus on the interview in an orderly and structured manner; for instance: (1) the experiences and beliefs that the participants have and hold concerning the tenets of knowledge and knowing (e.g., "From your understanding, based on personal experience, what is knowledge to you?", (2) the type(s) of learning approach that the participants align themselves with in their learning (e.g., "Explain how you study each day, say, after a lecture or a tutorial" , (3) the participants' historical and social backgrounds (e.g., "Tell me a bit about your growing up in the Solomon Islands").

Students in the South Pacific, in general, are relatively 'shy' and 'apprehensive' in the presence of authority figures. In particular, in the presence of lecturers on campus they are often quite courteous and humble in their mannerism. Because of this perplexity, we encouraged the participants to make prior visits and outings with us until they felt comfortable to proceed with the actual interview. The interview conducted with each participant was extensive and, in total, a period of 16 weeks was needed to complete the whole process with the 24 participants. Each participant was requested to visit us, officially, at least on three occasions (each occasion lasted approximately 2 hours). To create and promote a sense of intimacy in our interview, we encouraged the participants at the beginning of each interview session to talk about their own personal and social activities, etc, that happened during the week.

\section{Data recording and analysis}

We recorded the interviews by audio-taping and taking short notes during the interview session (Esterberg, 2002; Merriam, 1998). Researchers have recommended audiorecording of interviews, as this would allow the interviewer to devote his or her full attention and to ask probing questions and seek clarification (Legard et al., 2004). Tape recording the interviews in this study also permitted us to pay close attention to the participants' use of language, body gestures, and facial expressions. In transcribing our interviews, we used the suggestion made by Lofland, Snow, Anderson, and Lofland (2006, p. 108) where only deep, in- 
sightful, and detailed responses that were deemed valuable for analytic development were transcribed in their entirely. Furthermore, based on the research issues under investigation we analysed the transcribed data using both thematic and content analyses (Esterberg, 2002; Fraenkel \& Wallen, 2006; Spencer, Ritchie, O’Connor, 2004). In particular, having transcribed our raw data, we made personal and short notes for each interview for later articulation and discussion, if needed (Burns, 2000). Finally, we used the MAXqda2 software for PC (Qualitative Data Analysis; 2005) to assist us in the actual analysis.

In thematic analysis, we looked for emerging themes and patterns in responses from the 24 cases. We thematically analysed our data using a two-step procedure of coding that has often been implemented in grounded theory research (Esterberg, 2002; Strauss \& Corbin, 1998). This two two-step process of coding essentially involves open coding and focused coding. In open coding, we analysed our data at a microanalytical level looking and identifying themes and categories that were considered important and relevant to the line of inquiry in this study. Some recurring themes we identified included, for example: the meaning of knowledge and knowing, learning at USP in general, knowledge and learning, informally, from the South Pacific community, the contribution of society and culture at large, the importance of authorities and culture, and the notion of respect and honesty.

Having identified some recurring themes, we refined the process using focused coding (Coffey \& Atkinson, 1996). This process, similar to open coding, focuses specifically on the recurring themes we identified earlier. In this analysis, the refined focus indicated a number of specific themes; for example: knowledge is created by humankind and acquired from those who are in power or have high social status, understanding that personal knowledge is influenced by one's sociocultural settings, knowledge is evolving and is not static [personal epistemology]; and learning approaches depend on context, teaching pedagogies, and sociocultural settings, and the use of approach approaches depends on personal experience [learning approaches].

Having refined the recurring themes using the focused coding strategy, we then used content analysis to explore, by quantitative means, the frequencies of each of the themes identified. Content analysis, a methodological strategy that may be used with both qualitative and quantitative data (Burns, 2000; Fraenkel \& Wallen, 2006; McMurray, Pace, \& Scott, 2004), enables, for example, examination of quantitative categorisation as well as the development 
and clarification of theory (Millward, 2001; Wilson \& Hammond, 2001). From the open and focused coding strategies, we used quantitative content analysis to explore the frequency of occurrence in the themes and categories that were identified previously. Such quantification, in this case involving counting for example, enables us to make comparisons between participants in terms of their responses. Interpretation of content analysis may be made through the use of frequencies, a cross-break table, a chi-square analysis, or a narrative description derives from codes and themes. In our content analysis, we chose to use narrative description to highlight the themes identified.

\section{Discussion of findings}

The focus of this research study, differing from other studies, was to explore qualitatively two lines of inquiry, namely students' epistemological beliefs and their learning approaches in the South Pacific region. We advanced this research investigation from an exploratory perspective and that is not limited to theoretical grounding (e.g., Hofer \& Pintrich, 1997; Schommer, 1990, 1994a, 1994b) or quantitative empirical evidence. Most notably, students' beliefs about the nature of knowledge and knowing in this study were explored in context and from a personal sociocultural approach. Our description of the South Pacific and her peoples forms the premise for furthering the inquiry concerning the dialectical relationship between personal epistemology and learning approaches.

The two research inquiries that we addressed in this study were: (1) students' personal beliefs about the nature of knowledge and knowing, and how existing social milieus and personal sociocultural settings influence these beliefs, and (2) whether students' beliefs about the nature of knowledge and knowing relate to their preference and use of learning strategies. Key findings emerging from this study add theoretical contribution to the existing literature on personal epistemology and learning approaches. In particular, the evidence established provides a sociocultural perspective that differs from existing research studies conducted elsewhere in other social contexts (e.g., Chan \& Elliot, 2000; Phillips, 2001; Schommer-Aikins et al., 2005). 
Concerning the nature of knowledge, our findings of South Pacific students further the theoretical conceptions made previously (e.g., Hofer, 2000; Hofer \& Pintrich, 1997; Schommer, 1990) by indicating, for example, that students in this region see certain types of knowledge as being 'non-evolving', whereas other types are more changeable. For instance, the participants in general agreed that knowledge about nature, religion and personal moral values, say, is established from the outset and cannot be changed readily. Notably, the consensus made amongst the Solomon Islanders and Kiribati, in particular, is that there are certain types of knowledge that are 'divined' and spiritual in nature. In this analysis, we note an important element of religious beliefs, and that students to a large extent attribute certain types of knowledge to the creation of God himself/herself.

In contrast, knowledge pertaining to science, mathematics, or any other knowledge that is concerned with formal education and learning is perceived as changeable in nature and not fixated to a particular time or place. The participants expressed strongly the notion of formal knowledge, or what is perceived as being relevant to formal education and the development of society at large, as evolving continuously. In the following dialogue ${ }^{1}$, for example, one participant is discussing the connection between knowledge and religious beliefs:

[Researcher]: Do you see knowledge as a scientific matter that is created by man and woman, and that it is forever changing?

[Tevita ${ }^{2}$ ]: In my view, I see knowledge as being something that is handed down to us by nature itself. This is because God has created nature. We, as human beings, are part of nature, and because of this the Almighty has given us certain types of knowledge from the moment we come into this world. However, I also believe that there other types of knowledge that are created by science and man himself. For example, scientists use their prior knowledge to invent, discover, explore new happenings, and men and women use this knowledge with their existing ideas to create new knowledge.

\footnotetext{
${ }^{1}$ Given that English is a second or third language for the majority of the students in the South Pacific, grammatical errors may be seen, and are not corrected by us to preserve the entirety of the transcript and discussion. The same applies for the rest of the presentation shown in the subsequent sections.

${ }^{2}$ Pseudonyms are used for all participants to whom reference is made.
} 
[Researcher]: If that is the case, what do you see as being handed down by God and, likewise, what do you see as being scientific and created by man or woman?

[Tevita]: I see the ability to communicate clearly with one another and, say, to hunt and to fish in our village as being natural, and given to us by God himself. On the other hand, I see biology, chemistry, and educational psychology, for example, as being scientific, and create by scientists themselves. These areas are always changing and we update what we learn from these areas daily.

[Researcher]: In your view then, do you see knowledge as being made up of different types and that they evolve differently?

[Tevita]: On one hand I see knowledge as something that is there and always will be there. On the other hand, there are some things in life that I see as changing all the time. For example, your teaching of us the theory on constructivism. That will change surely.

Examination of the evidence also emphasises the importance of where knowledge originates from. There is a collective belief amongst the participants that knowledge, in the formal sense, originates from society. In particular, the emphasis is made especially towards those who are in authority or who hold high social status and power. There is a concerted feeling of respect for those who have the capacity and in a position to provide knowledge to the less educated ones. According to the participants, scientific knowledge or knowledge that is relevant to formal education is seen to reside specifically in external authority figures. In particular, there is a strong reverence amongst many individuals in the South Pacific for those who have wisdom and insightful knowledge to transmit this knowledge to others. In this analysis, the evolution of knowing, differing from Baxter Magolda (1992) and King and Kitchener (1994), rests predominantly on the authority figure, in this case, a lecturer or a tutor. This view supports previous theoretical contentions concerning the demeanour of students in this region (Nabobo-Baba, 2006; Ninnes, 1991; Phan, 2007). Aligning to this conduct is the status quo of silence and respect, as well as the acceptance of truth in knowledge from those who are revered by society. This indication, as shown from the following dialogue, suggests the difference in beliefs in the nature of knowing between those reported elsewhere and students in this region:

[Researcher]: Who do you think is responsible for your learning, or the knowledge that you have acquired? 
[Danietta]: I see those who are in authority like you as being the sole provider of my learning and knowledge. We, in this region, don't question those who are in authority...... for example, lecturers, teachers, priests, and village chiefs. We were told at an early age by our parents that if you question a teacher or a chief, that it was rude and forbidden. At USP, if we are seeing doing that (i.e., questioning a lecturer) your friends would ostracise you and call you 'show off' or 'she thinks she shows too much'. Because of this belief, we always see learning or knowledge as being given to us by others and we don't question this. Because of this, you will see a lot of the students like to sit there passively and not get involved actively.

Notably, findings emerged from our study indicate the importance of the sociocultural context. Interestingly, consistent with our theorisation, the participants placed emphasis on their sociocultural upbringing. Given these participants have had two lectures on Vygotsky's $(1978,1981)$ sociocultural theories of development, and the theory of social constructivism, it is not surprising perhaps to find that they related their discussion of personal epistemology and learning approaches in reference to these two theoretical frameworks. For instance, the participants referred specifically to the socio-historical background of a person, and how this contributes to the beliefs that one holds in regard to knowledge and knowing. We noted, in particular, the reference made towards the South Pacific region and her sociocultural ethos and values in shaping individuals' beliefs about knowledge and knowing. As alluded previously, there is a strong feeling of religious fundamentalism that closely links with certain types of knowledge. More importantly, however, there is a general agreement amongst the participants in this study, as well as our observations of on-campus students at USP, that the quality of knowledge and how much one acquires (whether successful or not) are to a large extent determined by 'external' sources. External sources, according to students in general, have a number of connotations, important amongst them being the authority figure (e.g., someone who has social status - a village chief, or a teacher), the social settings, and the cultural ethos and values that define the region as a whole.

Many students, in general, consider the interpretation of knowledge and one's own social and intellectual development as being influenced by the social settings and upbringing of a person. The participants' dialogues coincide with the theoretical postulation we made previously concerning the contention that one's social and cultural milieus may, in fact, govern 
existing mindset and practice. For example, the mindset of many individuals in this region, as explained by the participants, is that as a collective whole they are bounded by the environment, culture, and time when it comes to knowledge and learning. There is, in fact, no flexibility or controllability when considering the acquirement of knowledge. They suggested how individuals perceive, view, and conceive knowledge, as well as the choice they have in learning are tied to one's birthplace and subsequent upbringing. It is interesting to note that some of the participants, based their understanding of Vygotsky's $(1978,1981)$ sociocultural theories of development and referred to the notion of 'enculturation of beliefs of knowledge and knowing'; for example.

[Artika]: I personally believe that, like you mentioned in the lecture, knowledge and .... how we come to get this, yeah, is connected with our environment and upbringing. What was the word that was used? Enculturation, right? Yeah I believe our knowledge, and referring back to our earlier discussion, is enculturated. What I mean by this is that, I feel that where we come from, born, or raise plays an important role in determining our knowledge. When I was growing up, my parents used to me all sorts of things that differed from the Fijians'. Although we live in the same country, our culture and upbringing separate our beliefs about knowledge and going to school.

[Selina]: I feel that where you were born and raised play an important role in determining your understanding of knowledge and what you learn. For example, our upbringing in the Solomon Islands compared to the Indo-Fijians in Fiji influences our beliefs of what knowledge or learning should be about. The Kiribati students, because they are Micronesian and we are Melanesian, will tell you that they see knowledge differently. And they will learn differently, too. I think this is important. I don't think you can say all of us around the world will see knowledge as being the same. We will all have different views and meanings to knowledge. For example, if you ask an Indo-Fijian student what a book is, he will tell you what it means. It's like that situated learning that you were talking about in class.

Extrapolation of these dialogues reflects a similar line of argument in previous research, concerning the origins of learning, motivation, and identity that are bounded in the sociocultural background of each individual (McCaslin \& Hickey, 2001; McInerney, 2004; 
Summers, 2006). It would seem then, based on the participants' discussion, that the nature of knowledge itself is perceived as situated in a particular setting and takes into account the individual's sociocultural background. The discourse pertaining to the sociocultural settings of individuals, in our view, supports the religious sentiments outlined previously by the participants. In this analysis, it would appear that one's own upbringing instils certain beliefs about what knowledge should entail. Many individuals in this region, including the participants in this study, would claim that their ability to grasp knowledge and to learn and acquire skills is dependent and determined by the sociocultural environment at large. Their understanding of a concept (or absence thereof), for example, or the failure to succeed academically is the product of their own society and culture. The majority of the participants all agreed, for example, that the ability to learn is not fixed, but is dependent and influenced by the nurturing and rearing that take place, as a result of one's social and cultural settings. More importantly, the emphasis lies in the acquisition of resources and cultural tools (e.g., technological advances) that are offered by a particular society to assist one in acquiring learning. This line of reasoning is exemplified by one of the students:

[Siosefa]: It does matter why and for what purpose when one is at a particular place. The probability of what you know depends very much from your environment. What the environment offers you will help to you learn or not. To make my idea clear, I would like to give an example. Let's say you are growing up in an island which is very small and only a few people staying there. It is very hard for these people or what is on the island to share with us what they know, or to teach you how to learn. So because of this, when I compare my country with other countries, such as Australia or New Zealand, there are a lot of differences which influence learning. For example, in Australia they have more technologies that can help people learn. Here, in Tonga on a remote island, we don't even have electricity.

In total, examination of the evidence suggests a number of aspects that provide fruitful information concerning the beliefs that students at USP hold. The element of our study that differs somewhat from existing research (e.g., Phillips, 2001; Schommer-Aikins et al., 2005) is the important emphasis on one's sociocultural settings. In particular, in contrast to the work of Chan and Elliot (2000) and Phan (2006, 2008a), our findings suggest that the sociocultural 
background of an individual contributes to the personal epistemological beliefs that he or she holds in learning.

\section{Relationship between epistemological beliefs and learning approaches}

Analysis of the evidence, outlined in the preceding sections, indicates the importance of beliefs concerning the nature of knowledge and, to an extent, knowing. The approach that one takes towards learning, according to our theoretical postulation, may also be explained by the social and cultural settings of an individual. To a large extent, a number of studies (Mugler \& Landbeck, 1997; Phan \& Deo, 2007; Richardson et al., 1995) conducted in the South Pacific and elsewhere have alluded to the understanding that one's approaches to learning may be grounded socially, culturally, and contextually. Our findings provide relevant insight into the approaches of learning that students at USP take to assist them in their learning.

The participants' responses indicate, importantly, a learning approach that is shaped and nurtured by the sociocultural background of an individual. Furthermore, the participants indicated that their preference for a particular learning approach to learning is influenced, in part, by the types of teaching pedagogies that are used by lecturers and tutors. Consistent with the theoretical contentions made previously (Mugler \& Richardson, 1997; Phan \& Deo, 2007), our findings suggest that the upbringing of an individual plays a pivotal role in affecting the preference and orientation of learning approach. According to one participant, the upbringing of Indo-Fijians instils a strong belief of academic competition and competency. This 'indoctrination' and the pressure to excel academically result, in many cases, the need by individuals to do whatever it is necessary to fulfil their objectives and expectations. This reasoning, reflecting similarly the argument that has been portrayed in previous research (Phan, 2008c; Phan \& Deo, 2007), suggests that students from an early age are institutionalised and encouraged to engage in rote learning and memorisation in order to pass examinations, quizzes, tests, etc. There is a collective feeling amongst the non-Indo-Fijian participants also, that the need to compete and live up to society and parents' expectations compels them to engage in 'quick learning'; for example, as indicated by one of the Solomon Islanders:

[Linah]: I approach my learning by summarising the lecture notes into my own notes. I then read them just a couple of days before a test, and basically try to memorise them until I remember the notes. Then when I feel that I've properly 
understood the notes, I would try answering questions from past exam papers or from previous exercises without looking at the notes.

The extent to which students orientate towards a particular learning approach is also, in part, influenced by the teaching subject domain. This acknowledgement is consistent with previous research studies (Entwistle \& Ramsden, 1983; Lonka \& Lindholm-Ylanne, 1996; Smith \& Miller, 2005) that show the influence of discipline of study on learning approaches. We noted in this study, for example, the participants prefer the use of problem-solving in subject areas (e.g., mathematics, physics) that involve solving 'quantitative' questions, etc. This still does not exclude the fact that students engage in problem solving at a surface level, repeating and memorising the procedures involved until they are able to recall them successfully. There is, in this summation, the notion that students are still bounded by quick and surface learning. The different strategies (e.g., summarising and memorising, problem solving) are still subsumed within the paradigm of surface learning and the ability to demonstrate academic competency.

The sociocultural settings of the South Pacific also make a unique contribution towards learning approaches. In particular, the Pacific Islanders often prefer learning together. On-going dialogues and informal group discussions are a norm and a preference for many of the Solomon Islanders, Kiribati, and Tongan students at USP. As indicated by one of the Tongan participants, it is during these informal group discussions that students then get a chance to ask each other questions, and to express their own doubts and beliefs about a subject matter. More importantly, the group discussions enable students to compare notes and to assist each other with ideas and knowledge for better understanding. The use of reciprocal teaching and clarification is a major element in these group discussions. In fact, from the dialogue shown below, there is a feeling of interdependence that arises from students participating in group discussions; for example:

[Ana]: Another approach that I really like is through discussion with my friends. By discussion, we all get a chance to help each other, like sharing their ideas and I jot them down for better understanding. We really like studying together because all of us get a chance to help each other, and we all depend on each other for success. 
Furthermore, the impetus of our findings lies in the view from the participants that knowledge in itself serves a meaningful purpose. Accordingly, there is a strong feeling amongst all participants that knowledge, in the formal sense, serves as a formidable vehicle that enables social mobility and good prospect. Students at large see formal learning as a means of eluding from poverty and hardship. We refer back to our earlier discussion where the participants also hold the view that knowledge, to an extent, is divined and religious in origins. There is a conflicting view then where knowledge, according to the majority of individuals in this region, is also concerned with economic rationalism. Knowledge is regarded as a medium that perpetuates social and economic development and, consequently, students are encouraged earlier on in life to do whatever it is necessary or appropriate to achieve their educational goals. This understanding leads to the acceptance of quick and surface learning as a norm and a preference for the majority of the students at USP.

\section{Summation and conclusion}

The present study is significant in its attempt to explore the evolution of personal epistemology and learning approaches from a qualitative perspective. In particular, our examination of tertiary students of Indo-Fijian and Pacific Islander origins is unique as the information collected is more illuminative of the influence of one's social and cultural settings. Predominantly, the premise of our study, based on previous theoretical contentions (Baxter Magolda, 1987; Hofer \& Pintrich, 1997; Schommer, 1990), postulates the enculturation of personal epistemology and learning approaches of tertiary students. To a large extent, the evidence we established has provided additional information to the beliefs concerning the nature of knowledge and how individuals view learning and approaches to their learning.

Despite the significant findings of our research investigation, there are some existing limitations that warrant further consideration in future studies. First, this study was based on a small sample of students and does not therefore permit us to make generalisation. The evidence attesting to the importance of the sociocultural origin of an individual must be viewed and interpreted cautiously. Indeed, the South Pacific is perhaps the most culturally diverse region in the world with many cultural and linguistic groups. The 24 students that we interviewed cannot possibly be representative of the South Pacific region as a whole. Second, this region is developing in social, economical, and democratic terms, and it is perhaps not unexpected or uncommon for the participants to express the views and beliefs that they have. One 
could speculate that in a more developed region, students' sociocultural origins would vastly differ, leading to perhaps different accounts of epistemological beliefs and learning approaches. The collective nature of the South Pacific, in contrast to the Western ideology of independence, is a major impact on students' personal beliefs about knowledge and knowing. Future research could extend our investigation to another sociocultural setting; this would provide a comparative perspective into the evolution of personal epistemology and learning approaches from different cultures. Third, interviewing students at one point in time cannot capture the full essence or range of epistemological beliefs of individuals. The experience of an individual at different points in time affects the development of epistemological beliefs. Potential studies could involve observation or ongoing dialogue more frequently and over a longer time span.

\section{References}

Akande, A. (1998). Towards the multicultural validation of a western model of student approaches to learning. Education, 119(1), 37-47.

Baxter Magolda, M. B. (1987). The affective dimension of learning: Faculty-student relationships that enhance intellectual development. College Student Journal, 21, 46-58.

Baxter Magolda, M. B. (1992). Knowing and reasoning in college: Gender-related patterns in students' intellectual development. San Francisco: Jossey Bass.

Biggs, J. (1987). Student approaches to learning and studying. Melbourne: Australian Council for Educational Research.

Biggs, J., Kember, D. \& Leung, D. Y. P. (2001). The revised two-factor Study Process Questionnaire: R-SPQ-2F. British Journal of Educational Psychology, 63(3), 133-149.

Brewer, J. D. (2005). Ethnography. Philadelphia, Open University Press.

Buehl, M. M. \& Alexander, P. A. (2005). Motivation and performance differences in students' domain-specific epistemological belief profiles. American Educational Research Journal, 42(4), 697-726.

Burns, R. B. (2000). Introduction to research methods ( $4^{\text {th }}$ ed.). Pearson Education Australia: Longman.

Cano, F. (2005). Epistemological beliefs and approaches to learning: Their change through secondary school and their influence on academic performance. British Journal of Educational Psychology, 75, 203-221. 
Chan, K-W. \& Elliot, R. G. (2000). Exploratory study of epistemological beliefs of Hong Kong teacher education students: Resolving conceptual and empirical issues. Asia-Pacific Journal of Teacher Education, 28(3), 225-234.

Chen, C., Stevenson, H. W., Hayward, C., \& Burgess, S. (1995). Culture and academic achievement: Ethnic and cross-national differences. Advances in Motivation and Achievement, 9, 119-151.

Coffey, A. \& Atkinson, P. (1996). Making sense of qualitative data: Complementary research strategies. Thousand Oaks, CA: Sage.

Drew, P. \& Watkins, D. (1998). Affective variables, learning approaches and academic achievement: A causal modeling investigation with Hong Kong tertiary students. British Journal of Educational Psychology, 68, 173-188.

Entwistle, N. J. \& Ramsden, P. (1983). Understanding student learning. Nichols Publishing Company.

Esterberg, K. G. (2002). Qualitative methods in social research. Boston: McGraw-Hill.

Fraenkel, J. R. \& Wallen, N. E. (2006). How to design and evaluate research in education ( $^{\text {th }}$ ed.). Boston: McGraw-Hill.

Hofer, B. K. (2000). Dimensionality and disciplinary differences in personal epistemology. Contemporary Educational Psychology, 25, 378-405.

Hofer, B. K. (2001). Personal epistemology research: Implications for learning and teaching. Journal of Educational Psychology Review, 13(4), 353-383.

Hofer, B. K. (2004). Exploring the dimensions of personal epistemology in differing classroom contexts: Student interpretation during the first year of college. Contemporary Educational Psychology, 29, 129-163.

Hofer, B. K. \& Pintrich, P. R. (1997). The development of epistemological theories: Beliefs about knowledge and knowing and their relations to learning. Review of Educational Research, 67, 88-140.

Kember, D. (2000). Misconceptions about the learning approaches, motivation and study practices of Asian students. Higher Education, 40, 99-121.

Kember, D. \& Gow, L. (1991). A challenge to the anecdotal stereotype of the Asian student. Studies in Higher Education, 16, 117-128.

Kember, D. \& Leung, D. Y. P. (1998). The dimensionality of approaches to learning: an investigation with confirmatory factor analysis on the structure of the SPQ and LPQ. British Journal of Educational Psychology, 68, 395-407. 
Kervin, L., Vialle, W., Herrington, J., \& Okely, T. (2006). Research for educators. Victoria, Australia: Thomson Social Science Press.

King, P. M. \& Kitchener, K. S. (1994). Developing reflective judgment: Understanding and promoting intellectual growth and thinking in adolescents and adults. San Francisco: Jossey Bass.

Kitchener, K. S. \& King, P. M. (1981). Reflective judgment: Concepts of justification and their relationship to age and education. Journal of Applied Developmental Psychology, 2, 89-116.

Kvale, S. (1996). Interviews: An introduction to qualitative research interviewing. Thousand Oaks, CA: Sage.

Legard, R., Keegan, J., \& Ward, K. (2004). In-depth interviews. In J. Ritchie \& J. Lewis (Eds.), Qualitative research practice, pp. 138-169. Thousand Oaks, CA: Sage.

Lofland, J., Snow, D., Anderson, L., \& Lofland, L. H. (2006). Analyzing social settings: A guide to qualitative observation and analysis $\left(4^{\text {th }}\right.$ ed.). Belmont, CA: Thomson Wadsworth.

Lonka, K. \& Lindholm-Ylanne, S. (1996). Epistemologies, conceptions of learning, and study practices in medicine and psychology. Higher Education, 31(1), 5-24.

Markus, H. R. \& Kitayama, S. (1991). Culture and the self: Implications for cognition, emotion, and motivation. Psychological Review, 98, 224-253.

Marton, F. \& Säljö, R. (1976). On qualitative differences in learning - I: Outcome and process. British Journal of Educational Psychology, 46, 4-11.

McCaslin, M. \& Hickey, D. T. (2001). Educational psychology, social constructivism, and educational practice: A case of emergent identity. Educational Psychologist, 36, 133-140.

McInerney, D. M. (2004). A discussion of future time perspective. Educational Psychology Review, 6(2), 141-151.

McMurray, A. J., Pace, R. W., \& Scott, D. (2004). Research: A commonsense approach. Southbank Victoria: Thomson Social Science Press.

Merriam, S. B. (1998). Qualitative research and study applications in education. San Francisco: Jossey Bass.

Millward, L. J. (2001). Focus groups. In G. M. Breakwell, S. Hammond, \& C. Fife-Schaw (Eds.), Research methods in psychology, pp. 303-324. Thousand Oaks, CA: Sage.

Mugler, F. \& Landbeck, R. (1997). Learning in the South Pacific and phenomenography across cultures. Higher Education Research and Development, 16, 227-239. 
Muis, K. R. (2004). Personal epistemology and mathematics: A critical review and synthesis of research. Review of Educational Research, 74(3), 317-377.

Murphy, S. M. \& Tyler, S. (2005). The relationship between learning approaches to part-time study of management courses and transfer of learning to the workplace. Educational Psychology, 25, 455-469.

Nabobo-Baba, U. (2006). Knowing and learning: An indigenous Fijian approach. Institute of Pacific Studies, USP, Suva.

Ninnes, P. (1991). Culture and learning in Western Province, Solomon Islands. MA thesis, Flinders University, Western Australia.

Nist, S. L. \& Holschuh, J. P. (2005). Practical applications of the research on epistemological beliefs. Journal of College Reading and Learning, 35(2), 84-92.

Patton, M. Q. (1990). Qualitative evaluation methods (2 ${ }^{\text {nd }}$ ed.). Thousand Oaks, CA: Sage.

Peng, H. \& Fitzgerald, G. E. (2006). Relationships between teacher education students' epistemological beliefs and their learning outcomes in a case-based hypermedia learning environment. Journal of Technology and Teacher Education, 14(2), 255-285.

Perry, W. G., Jr. (1970). Forms of intellectual and ethical development in the college years. New York: Academic Press.

Phan, H. P. (2006). Examination of student learning approaches, reflective thinking, and epistemological beliefs: A latent variables approach. Electronic Journal of Research in Educational Psychology, 10, 4(3), 577-610.

Phan, K. P. (2007). An examination of reflective thinking, learning approaches, and selfefficacy beliefs at the University of the South Pacific: A path analysis approach. Educational Psychology, 27(6), 789-806.

Phan, H. P. (2008a). Predicting change in epistemological beliefs, reflective thinking, and learning approaches: A longitudinal study. British Journal of Educational Psychology, 78, 75-93.

Phan, H. P. (2008b). Multiple regression analysis of epistemological beliefs, learning approaches, and self-regulated learning. Electronic Journal of Research in Educational Psychology, 6(1), 157-184.

Phan, H. P. (2008c). Unifying different theories of learning: Theoretical framework and empirical evidence. Educational Psychology, 28(3), 325-340.

Phan, H.P. \& Deo, B. (2006). Approaches to learning in educational psychology and mathematics: A comparative analysis in the South Pacific region. A refereed article published 
for the Australian Association for Research in Education, $26^{\text {th }}-30^{\text {th }}$ November. South Australia, Australia.

Phan, H. P. \& Deo, B. (2007). The revised learning process questionnaire: A validation of a Western model of students' study approaches to the South Pacific context using confirmatory factor analysis. British Journal of Educational Psychology, 77, 719-739.

Phan, H. P. \& Deo, B. (in press). "Revisiting" the South Pacific approaches to learning: A confirmatory factor analysis study. Higher Education Research and Development.

Phillips, F. (2001). A research note on accounting students' epistemological beliefs, study strategies, and unstructured problem-solving performance. Issues in Accounting Education, 16(1), 21-39.

Puamau, P. (2002). Rethinking education in Fiji: Issues and solutions in the $21^{\text {st }}$ century. In F. Pene, A. M. Taufe'ulungaki, \& C. Benson (Eds.), Tree of opportunities: Re-thinking Pacific education. The University of the South Pacific and the Institute of Education, Suva.

Ramsden, P. (1979). Student learning and perceptions of the academic environment. Higher Education, 27, 449-468.

Richardson, J. T. E. (1994). Cultural specificity of approaches to studying in higher education. Higher Education, 27, 449-468.

Richardson, J.T.E., Landbeck, R. \& Mugler, F. (1995). Approaches to Studying in Higher Education: a comparative study in the South Pacific. Educational Psychology, 15(4), 417432.

Robson, C. (2002). Real world research ( $2^{\text {nd }}$ ed.). Oxford: Blackwell.

Rubin, A. \& Babbie, E. R. (2008). Research methods for social work (6 ${ }^{\text {th }}$ ed.). Belmont, CA: Thomson Brooks/Cole.

Ryan, M. P. (1984). Monitoring text comprehension: Individual differences in epistemological standards. Journal of Educational Psychology, 76, 248-258.

Schommer, M. (1990). Effects of beliefs about the nature of knowledge on comprehension. Journal of Educational Psychology, 82, 498-504.

Schommer, M. (1993). Epistemological development and academic performance among secondary students. Journal of Educational Psychology, 85(3), 406-411.

Schommer, M. (1994a). An emerging conceptualisation of epistemological beliefs and their role in learning. In R. Garner \& P. A. Alexander (Eds.), Beliefs about text and instruction with text, (pp. 25-40). Hillsdale, NJ: Lawrence Erlbaum.

Schommer, M. (1994b). Synthesizing epistemological beliefs research: Tentative understandings and provocative confusions. Educational Psychology Review, 6(4), 293-319. 
Schommer, M. (1998). The influence of age and education on epistemological beliefs. British Journal of Educational Psychology, 68, 551-562.

Schommer, M., Crouse, A. \& Rhodes, N. (1992). Epistemological beliefs and mathematical text comprehension: Believing it's simple doesn't make it so. Journal of Educational Psychology, 84, 435-443.

Schommer-Aikins, M. (2002). An evolving theoretical framework for an epistemological belief system. In B. K. Hofer \& P. R. Pintrich (Eds.), Personal epistemology: The psychology of beliefs about knowledge and knowing (pp. 103-118). Mahwah, NJ: Erlbaum.

Schommer-Aikins, M., Duell, O. K. \& Hutter, R. (2005). Epistemological beliefs, mathematical problem-solving beliefs, and academic performance of middle school students. The Elementary School Journal, 105(3), 289-304.

Schommer-Aikins, M. \& Hutter, R. (2002). Epistemological beliefs and thinking about everyday controversial issues. The Journal of Psychology, 136(1), 5-20.

Schraw, G. \& Sinatra, G. M. (2004). Epistemological development and its impact on cognition in academic domains. Contemporary Educational Psychology, 29, 95-102.

Smith, S. N. \& Miller, R. J. (2005). Learning approaches: Examination type, discipline of study, and gender. Educational Psychology, 25(1), 43-53.

Spencer, L., Ritchie, J., \& O’Connor, W. (2004). Analysis: Practices, principles, and processes. In J. Ritchie \& J. Lewis (Eds.), Qualitative research practice, pp. 199-218. Thousand Oaks, CA: Sage.

Strauss, A. \& Corbin, J. (1998). Basis of qualitative research: Techniques and procedures for developing grounded theory. Thousand Oaks, CA: Sage.

Summers, J. J. (2006). Effects of collaborative learning in math on sixth graders' individual goal orientations from a socioconstructivist perspective. The Elementary School Journal, 106(3), 273-290.

Taufe'ulungaki, A. M. (2003). Vernacular languages and classroom interactions in the Pacific. In K. H. Thaman (Eds.), Educational ideas from Oceania: Selected readings. The Institute of Education, UNESCO Chair of Teacher Education and Culture. USP, Suva.

Teaero, T. F. (2002). Old challenges, 'New' responses to educational issues in Kiribati. In F. Pene, A. M. Taufe'ulungaki, \& C. Benson (Eds.), Tree of opportunities: Re-thinking Pacific education. The University of the South Pacific and The Institute of Education, Suva.

Thaman, H. K. (1999). Towards culturally democratic teacher education. In K. H. Thaman \& C. Benson (Eds.), Pacific cultures in the teacher education curriculum. The Institute of Education, USP, Suva. 
Triandis, H. C. (1989). The self and social behavior in differing cultural contexts. Psychological Review, 96(3), 506-520.

Triandis, H. C., Bontempo, R., Villareal, M. J., Asai, M. \& Lucca, N. (1988). Individualism and collectivism: Cross-cultural perspectives on self-ingroup relationships. Journal of Personality and Social Psychology, 54(2), 323-338.

Vygotsky, L. (1978). Mind in society: The development of higher psychological processes. Cambridge, MA: Harvard University Press.

Vygotsky, L. (1981). The genesis of mental functioning. In J. V. Wertsch (Ed.), The concept of activity in Soviet psychology, pp. 144-188. Armonk, NY: Sharpe.

Watkins, D. (2001). Correlates of approaches to learning: A cross-cultural meta-analysis. In R. Sternberg \& L. F Zhang (Eds.), Perspectives on thinking, learning, and cognitive styles, (pp. 165-195). Mahwah, NJ: Lawrence Erlbaum.

Watkins, D., Regmi, M. \& Astilla, E. (1991). The Asian learner as a rote learner stereotype: Myth or reality. Educational Psychology, 11, 21-34.

Wilson, M. \& Hammond, S. (2001). Structuring qualitative data using a scaling procedure. In G. M. Breakwell, S. Hammond, \& C. Fife-Schaw (Eds.), Research methods in psychology, pp. 281-293. Thousand Oaks, CA: Sage.

Wong, N-Y. \& Watkins, D. (1998). A longitudinal study of the psychosocial environmental and learning approaches in the Hong Kong classroom. Journal of Educational Research, 91(4), 247-254. 